\title{
The Impact of Virtual Reality on Mood States Prior to Blood Donation
}

\author{
Jeff Tarrant $^{1 *}$, John S Abrams ${ }^{2}$ and Rachel Jackson ${ }^{3}$ \\ ${ }^{1}$ NeuroMeditation Institute, USA \\ ${ }^{2}$ Clinical Endocannabinoid System Consortium (CESC, Inc.), USA \\ ${ }^{3}$ Department of Psychology, University of Oregon, USA
}

*Corresponding author: Jeff Tarrant, NeuroMeditation Institute, Eugene OR, USA

\begin{abstract}
Virtual Reality (VR) has shown promise as a non-pharmaceutical intervention for both anxiety and pain management. Consequently, specially designed VR experiences may be a useful tool to counteract anxiety during procedures that require a blood draw. In the current study we examined negative and positive mood states before and after a brief VR intervention at a Red Cross blood drive. Results demonstrated a significant increase in positive mood states (Happiness, Calmness) and a reduction of negative mood states (Tension, Fatigue). These results support the accumulating evidence that VR has the potential to act as a powerful and effective tool for anxiety and stress management in anxiety provoking situations.
\end{abstract}

Keywords: VR; Virtual reality; Healium; Blood donation; Anxiety; Stress; Needle Fear; Needle phobia

\section{Introduction}

Needle injections are an integral part of many medical procedures, yet "needle fear" and "needle phobia" frequently result in the avoidance of necessary treatments and an unwillingness to donate blood [1]. Studies examining fear of needles have reported prevalence estimates as high as $91 \%$ [2]. Because this anxiety has real life consequences, a recent review of research on needle fear recommended that "greater attention should be given to evidence-based approaches to alleviate fear during injections" [1]. When considering interventions to assist in the reduction of needle fear, virtual reality seems like an obvious choice. VR has already demonstrated its utility in the treatment of anxiety disorders including phobias and PTSD [3,4]. However, most of these studies incorporated VR into an existing therapeutic context, making it difficult to isolate the impact of the VR intervention from other aspects of treatment. One recent study examined the ability of a stand-alone VR experience to reduce state anxiety in an anxious population [5]. The results indicated that both the VR and a rest control condition significantly reduced reports of anxiety. However, only the VR experience shifted brainwave activity in a manner consistent with reduced nervous system arousal [5]. To our knowledge, only one study has specifically examined the use of VR during a blood draw. This study was conducted with a pediatric population and demonstrated that specific VR experiences significantly reduced pain and anxiety when compared to "treatment as usual" [6]. In the current study, we sought to explore the potential of using a calming VR experience to increase positive mood states and decrease negative mood states just prior to a needle stick at a community blood drive.

\section{Materials and Methods \\ Participants}

33 donors at a community Red Cross blood drive volunteered to participate. The study consisted of 19 females and 14 males aged 15 to $70(M=25.85, S D=16.35)$. All participants provided informed consent through the Red Cross.

\section{Materials}

\section{Virtual reality}

The VR experience used an Oculus Go headset with Healium software. A 4.5-minute guided experience encouraged the user to use their internal feeling state (positivity) to transform a VR landscape. The experience begins in a rather bleak setting with a large tree covered in graffiti. The area around the tree is barren with trash strewn about. As the experience progresses, the user is coached through engaging in feelings of positivity and gratitude which gradually transforms the tree and surrounding environment into a clean, lush landscape (see Figure 1). 


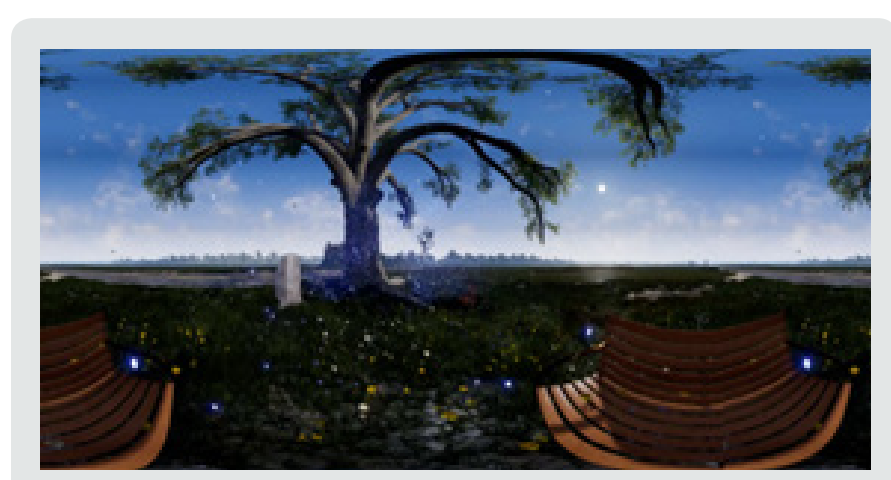

Figure 1: Screen shot of "The Big Tree" experience from Healium software..

\section{Brunel Mood Scale}

The Brunel Mood Scale [7] consists of 32 mood descriptors that are categorized into 8 unipolar dimensions: anger, tension, depression, vigor, fatigue, confusion, happiness, calmness. Using a response frame of "how do you feel right now?" subjects indicated the extent of their experience of the mood descriptors on a 5-point scale $(0=$ not at all, $1=$ a little, $2=$ moderately, $3=$ quite a bit, $4=$ extremely).

\section{Procedure}

Participants at a community blood drive were invited to experience "The Big Tree" virtual reality (VR) experience in the Healium software platform just prior to the needle stick. Participants completed the Brunel Mood Scale before and after the VR experience. A Matched Pair Analysis was used to examine pre - post significant differences for the 8 aggregated Brunel Mood Scores. The data were grouped by Mood to create an Across Group analysis.

\section{Results}

Table 1: Mean of Pre and Post Scores for the 8 aggregated Brunel Moods.

\begin{tabular}{|c|c|c|}
\hline Mood & Pre & Post \\
\hline Anger & 1.8 & 0.4 \\
\hline Calmness & 9.1 & $11.4^{*}$ \\
\hline Confusion & 2.4 & 1.4 \\
\hline Depression & 1.2 & 0.7 \\
\hline Fatigue & 5.7 & $3.2^{*}$ \\
\hline Happy & 10.2 & $11.7^{*}$ \\
\hline Tension & 3.9 & $1.1^{*}$ \\
\hline Vigor & 10.6 & 10.4 \\
\hline
\end{tabular}

A matched pairs analysis with time of testing (pre-post) as independent variables, and scores on the Brunel Mood Scale as dependent variables, showed a significant effect $(F(2,256)=52.79$, $\mathrm{p}<.0001$ ). The pre-post means for each scale are displayed in (Table 1). When presented as a Tukey mean-difference plot (see Figure 2 ), it is clear that 4 of the aggregate mood scores were significant
( $\mathrm{p}<.05)$. Specifically, Calmness and Happy increased from prepost while Tension and Fatigue decreased significantly from prepost.

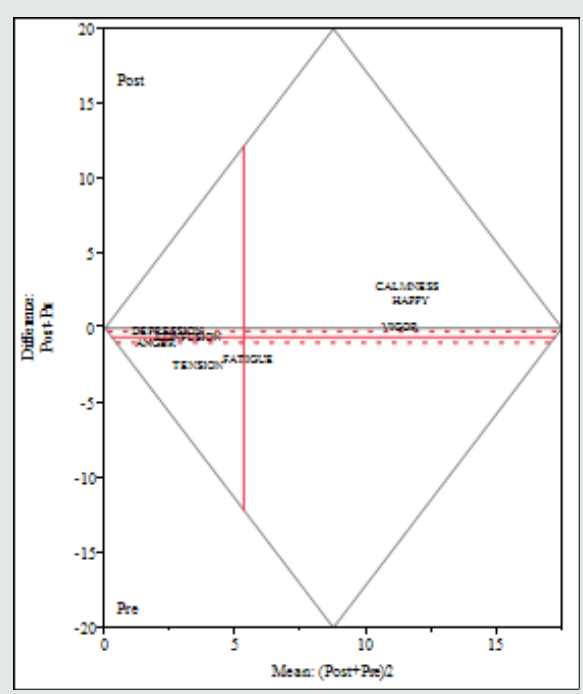

Figure 2: The Brunel Mood Dataset consisting of Pre and Post VR Guided Meditation session responses is presented as a Tukey mean-difference plot. Each aggregate Brunel Mood is positioned on the plot. The horizontal solid = mean and dashed $=95 \%$ Confidence Interval). Moods that fall above or below the dashed line showed a significant difference $(\mathrm{a}=0.05)$ between the Post and Pre scores.

\section{Discussion}

This study demonstrated that an inexpensive and brief VR intervention can have a significant positive impact on mood just prior to a needle stick, reducing tension and fatigue and increasing feelings of calmness and happiness in an adult population. This is consistent with other research showing that VR reduces pain and anxiety better than "treatment as usual" in a pediatric population during a routine blood draw [6]. The apparent success of VR in reducing anxiety may be, in part, due to the strong feeling of "presence" achieved in these environments [8,9]. "Presence," is defined as the subjective feeling of being in another place. As there are multiple visual and auditory cues in a traditional hospital or blood donation setting that could trigger or exacerbate an anxiety response, removal of these cues may be helpful in reducing anxiety. In addition, rather than simply removing a potentially stressful environment, VR can replace these stressful cues with an environment designed to be soothing, comforting, and mood enhancing. VR research for pain management has shown that this strategy works quite well. For example, VR experiences designed to assist burn victims often utilize visual scenes that include cold weather and snow, taking advantage of the brain's tendency to respond physiologically to environmental cues. A recent review of research examining VR for pain management in burn victims concluded that the addition of VR to dressing change or physical therapy sessions significantly reduced pain intensity, time spent thinking about pain, and unpleasantness [10]. The current study adds to the accumulating evidence that VR has the potential to 
make basic medical procedures, such as a blood draw, much more tolerable, potentially improving patient compliance and willingness to donate blood [11]. Obviously, this study lacked a control group and is therefore limited in the degree to which the results can be generalized. Future studies would benefit from using a randomized control procedure, allowing subjects to use the VR experience during the blood draw (rather than prior to the needle stick), and examining a variety of additional outcome measures as well as personality characteristics.

\section{References}

1. McLenon J, Rogers M (2019) The fear of needles: A systematic review and meta-analysis. Journal of Advances in Nursing 75(1): 30-42.

2. Naidu RS, Lalwah S (2010) Dental anxiety in a sample of West Indian adults. West Indian Medical Journal 59(5): 567-572.

3. Motraghi T, Seim R, Meyer E, Morissette S (2014) Virtual reality exposure therapy for the treatment of posttraumatic stress disorder: a methodological review using CONSORT guidelines. Journal of Clinical Psychology 70(3): 197-208.

4. Morina N, Ijntema H, Meyerbroker K, Emmelkamp P (2015) Can virtual reality exposure therapy gains be generalized to real-life? A meta-analysis of studies applying behavioral assessments. Behaviour Research Therapy 74: 18-24.

5. Tarrant J, Viczko J, Cope H (2018) Virtual reality for anxiety reduction demonstrated by quantitative EEG: A pilot study. Frontiers in Psychology.

6. Gold J, Mahrer N (2017) Is virtual reality ready for prime time in the medical space? A randomized control trial of pediatric virtual reality for acute procedural pain management. Journal of Pediatric Psychology 43(3): 266-275.

7. Soos I, Lane A, Leibinger E, Karasai I, Hamar P (2007) Validity of the Brunel Mood Scale for use with UK, pp: 119-130.

8. Riva G, Waterworth JA, Waterworth EL, Mantovani F (2011) From intention to action: The role of presence. New Ideas Psychology 29(1): 24-37.

9. Waterworth J, Riva G (2014) Feeling present in the physical world and in computer-mediated environments. Basingstoke: Palgrave Macmillan.

10. Luo H, Cao C, Zhong J, Chen J, Cen Y (2019) Adjunctive virtual reality for procedural pain management of burn patients during dressing change or physical therapy: A systematic review and meta-analysis of randomized controlled trials. Wound Repair and Regeneration 27(1): 90-101.

11. Wright S, Yelland M, Heathcote K, Ng SK, Wright G (2009) Fear of needles: Nature and prevalence in general practice. Australian Family Physician 38(3): 172-176.

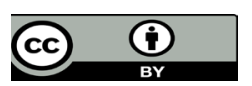

This work is licensed under Creative Commons Attribution 4.0 License

To Submit Your Article Click Here:

Submit Article

DOI: $10.32474 /$ SJPBS.2019.02.000150

\begin{tabular}{|l|l|}
\hline SJPBS & $\begin{array}{c}\text { Scholarly Journal of Psychology } \\
\text { and Behavioral Sciences }\end{array}$ \\
Assets of Publishing with us \\
\hline - Global archiving of articles
\end{tabular}

